\title{
Impact of Rail Infrastructure Maintenance Conditions on the Vehicle-Track Interaction Loads
}

\author{
Naim Kuka ${ }^{(1)}$, Caterina Ariaudo ${ }^{(2)}{ }^{*}$, Riccardo Verardi $^{(2)}$, João Pombo $^{(3,4)}$ \\ (1) Railway Dynamics \& Mechatronics - ALSTOM Transport \\ naim.kuka@alstomgroup.com \\ (2) Railway Dynamics - ALSTOM Ferroviaria S.p.A. \\ caterina.ariaudo@alstomgroup.com; riccardo.verardi@alstomgroup.com

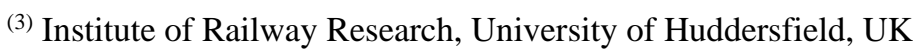 \\ j.pombo@hud.ac.uk \\ (4) IDMEC, Instituto Superior Técnico, Universidade de Lisboa, Portugal \& ISEL, IPL, Portugal \\ *Corresponding Author: caterina.ariaudo@alstomgroup.com
}

\begin{abstract}
The rail infrastructure and the track components are expensive assets with long life spans and high maintenance costs. The cost efficiency, performance and punctuality of train operations heavily depend on the track conditions. Ideally, the railway track would be completely smooth providing continuous support to the rolling stock running on it. In practice, however, the infrastructure cannot be installed without irregularities. These defects will increase over time due to the service loads imposed by the railway vehicles. The aim of this work is to use advanced computational tools to predict how the vehicles will respond to changing levels of track defects. For this purpose, the track and its maintenance conditions are characterized in realistic operation scenarios and modelled with detail in order to enable studying the interaction loads that are imposed to the vehicles by the track conditions. The presented methodology enables to identify the track health indexes that have higher influence on the dynamic loads transmitted to the rolling stock. It was observed that the track layout, track irregularities and degradation of the rails have the larger influence on the vehicle-track interaction loads with consequences in terms of safety and maintenance costs. In this way, this work contributes to the development of solutions with technological relevance, giving answer to the industry's most recent needs in terms of reducing the maintenance costs and decreasing the incidents that cause traffic disruptions, contributing to improve the competitiveness of the railway transport.
\end{abstract}

Keywords: Railway dynamics, Multibody systems, Vehicle-infrastructure interaction, Track geometry, Track maintenance.

\section{Introduction}

The health and long-time performance of the railway infrastructure is critical not only due to safety aspects but also owing to the high maintenance costs involved and the damage that it can cause to the vehicles. Despite its importance, the maintenance management of the track is, scientifically, one of the least understood and least 
predictable elements of railway systems. In reality, the maintenance of rail tracks generally relies on empirical data and on the return of experience, together with needs or conveniences linked to day-by-day operation, more than on the studies that analyse all the factors of damage, such as the characteristics of vehicle and track, the mission profile, the route traffic, to cite only the most importants.

The complexity and multidisciplinarity of the vehicle-track interaction is mainly due to a reciprocal process of causes and effects [1], as illustrated in Figure 1. The dynamic behaviour of the rail vehicles and the forces exchanged between vehicle and track depends on the macro-geometry and micro-geometry of the track (further to other boundary conditions), but they depends also by the vehicle design parameters and the health state of various components. Hence, the vehicle design and its health state affect the damage of track components and, vice-versa, the track condition affects the dynamic behaviour and the deterioration of the vehicle parts. In this view, the Figure 1 indicates the framework and the key parts of the vehicle/track system to be considered in simulation models and in the investigations dealing with performances and vehicle/track damage.

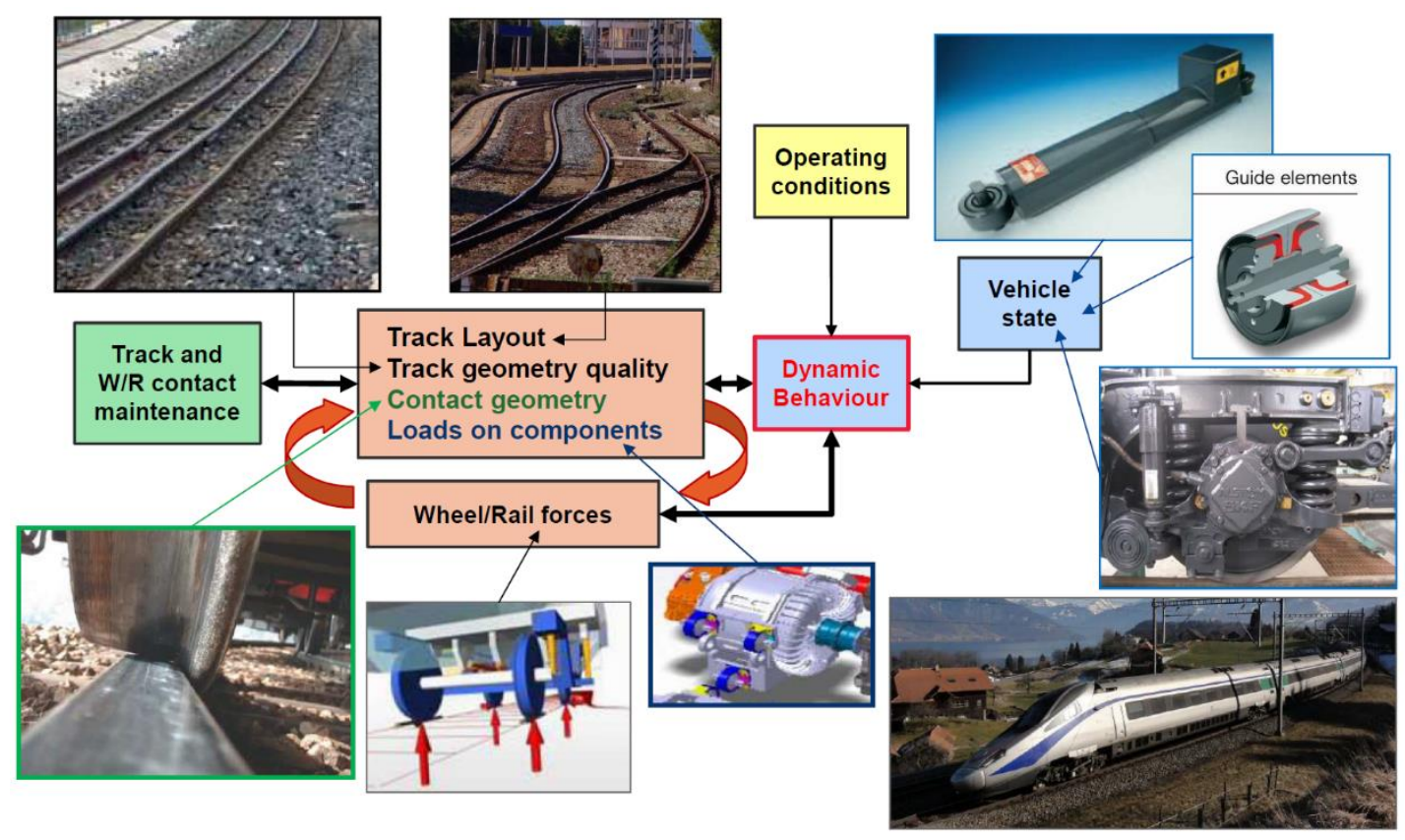

Figure 1: Overview of vehicle-track interaction and damage

Such studies require the use of advanced computational tools and experiments to validate models and de-risk the development of new technology. This involves using Multi-Body (MB) systems methodologies for railway vehicle dynamics to study different type of problems [2-5], including virtual homologation [6,7], study of the vehicle performance for selected tracks [8,9], derailments prevention [10-15], design of suspensions [16-18], tracks with complex geometries [19-22], traction or braking systems [23,24], pantograph-catenary interaction [25-35], just to mention a few.

The analysis of the track dynamic response has been object of many research works [36-42]. For this purpose, complex numerical models have been developed using MB 
and Finite Element (FE) methodologies for flexible tracks in co-simulation [43-46]. Other authors have dedicated their experimental research activities to investigate the performance of various parts of the railway track structure . For example, the dynamic performance and long-term behaviour of concrete slab and ballasted tracks were studied through full-scale model tests with simulated train moving loads [47-55].

The study of the interaction between the vehicle and the track consists of the solution of the contact between the wheels and the rails [56-63]. This issue plays a key role since it not only affects the motion of the vehicle but also allows to study the effect of track irregularities [64-67], the prediction of some damaging phenomena such as wear [68-75], rolling contact fatigue [76,77] or corrugation [78-80] and other track singularities [81-84].

In [1] a methodology to study how the varying characteristics of the vehicle components can impact on the vehicle-track interaction loads and on the track damage was illustrated. The present work aims to study how the rail infrastructure maintenance conditions can influence the vehicle-track interaction loads. The innovative scope of this work is related to the studies that are performed in realistic operations conditions, allowing to trace a path towards the genuine definition of load mission profiles to assess the structural fatigue of the vehicle and track components. The evaluation criteria and the quantities assessed in this work are defined according to EN 14363 [85] and supported by the comparison with available field data, which also represents an innovative feature of this work.

It is known that the track design parameters are not the same for all railway lines. The radii of the curves, the installed cant, the slope of the transition curves, type of rail, type of sleeper, type of fastening, ballast characteristics, the track gauge differ according to whether they are high-speed lines, regional or suburban lines. Over time, and also according to the type of rolling stock circulating on the lines, the various parameters change, giving rise to different conditions of wheel-rail contact, track irregularities with different wavelengths, isolated defects, etc. These conditions influence the dynamic behavior, i.e. vibrations and shocks and, ultimately, the dynamic loads on the track and on the vehicle components [6,86-91]. Therefore, to avoid failures and damages to the various components of the vehicle-track system, it is important to consider loads that are representative of the operating conditions of service, for example for the design of the truck fatigue in accordance with EN 15827 [92] or in the application of IEC 61373 [93] for random vibration and shock testing of pneumatic, electrical and electronic rail components. The study presented here addresses this problem in an innovative way by analysing the influence of the maintenance state of the track on the loads transmitted to the vehicle running on it. It is also demonstrated that a good maintenance strategy will bring benefits, in terms of reliability, availability and costs to the infrastructure managers, vehicle manufacturers and rail operators.

The study proposed here starts with the assessment of the vehicle-track interaction loads, varying the track conditions from new to degraded, with particular attention to the track quality and to the rail wear status, although remaining in the range of the admissible maintenance limits. The assessment is based on the vertical wheel-rail contact forces, the lateral track shift forces and the accelerations on bogie and carbody, as defined in the EN 14363 [85]. 


\section{Methodology}

The study mainly uses dynamic MB simulations that allow to consider the different track conditions, combined with the vehicle's mission profile, and to evaluate their impact on the loads exchanged between the vehicle and the track. Advanced computational tools are necessary to represent the characteristics of the track and of the vehicle, thus reproducing the real physical phenomena.

The study of the influence of the track maintenance state on the loads transmitted to the vehicles and vice-versa, can be performed following two different approaches, based mainly on tests or on simulations:

1. Analysis of the data measured by test vehicles, running on different levels of track quality and wear of the rails, provided that all the other boundary conditions, like the speed, friction, vehicle parameters, etc. remain unchanged;

2. Simulation of the dynamic behaviour of the trains under different conditions of wheel-rail contact and track maintenance state and compare the results, mainly in terms of wheel-rail contact forces and accelerations on the vehicle.

The second approach is the one followed here, having the advantage of a full control of the simulation conditions. It gives the possibility to investigate the relevant vehicletrack scenario and service conditions foreseen by the mission profile in any design phase. The main issue remains the availability of good and representative data, especially of the track, based not only on theoretical formulation, but possibly on real measurements. The approach used here is the same that was proposed in [1], i.e., to obtain realistic vehicle-track loads representative of the service conditions and useful for the fatigue dimensioning of the railway vehicle components.

\subsection{Multibody Tools}

The studies described here were conducted using the commercial MB codes SIMPACK and VAMPIRE [94], thanks to the potentialities offered by these two codes. In particular, the following characteristics have been exploited: (i) the use of full non-linear models with a number of degrees of freedom necessary and sufficient to represent the dynamic behavior of the train; (ii) the wheel-rail contact model representative of the wheel-rail forces in all simulation conditions; (iii) the possibility of introducing the track geometry (track layout and track irregularity) and the speed profile corresponding to the real mission profile of the train; (iv) calculation times not too much penalizing and a user-friendly post-processing.

\subsection{Track Model}

For the aim of this study, much care has been put in the model of the track, with a full characterization of the track layout, track irregularities, rail profiles and track stiffness/damping characteristics, as represented in Figure 2. The assessment of the importance of all these aspects, on the vehicle-track loads, will be the focus of this work. 


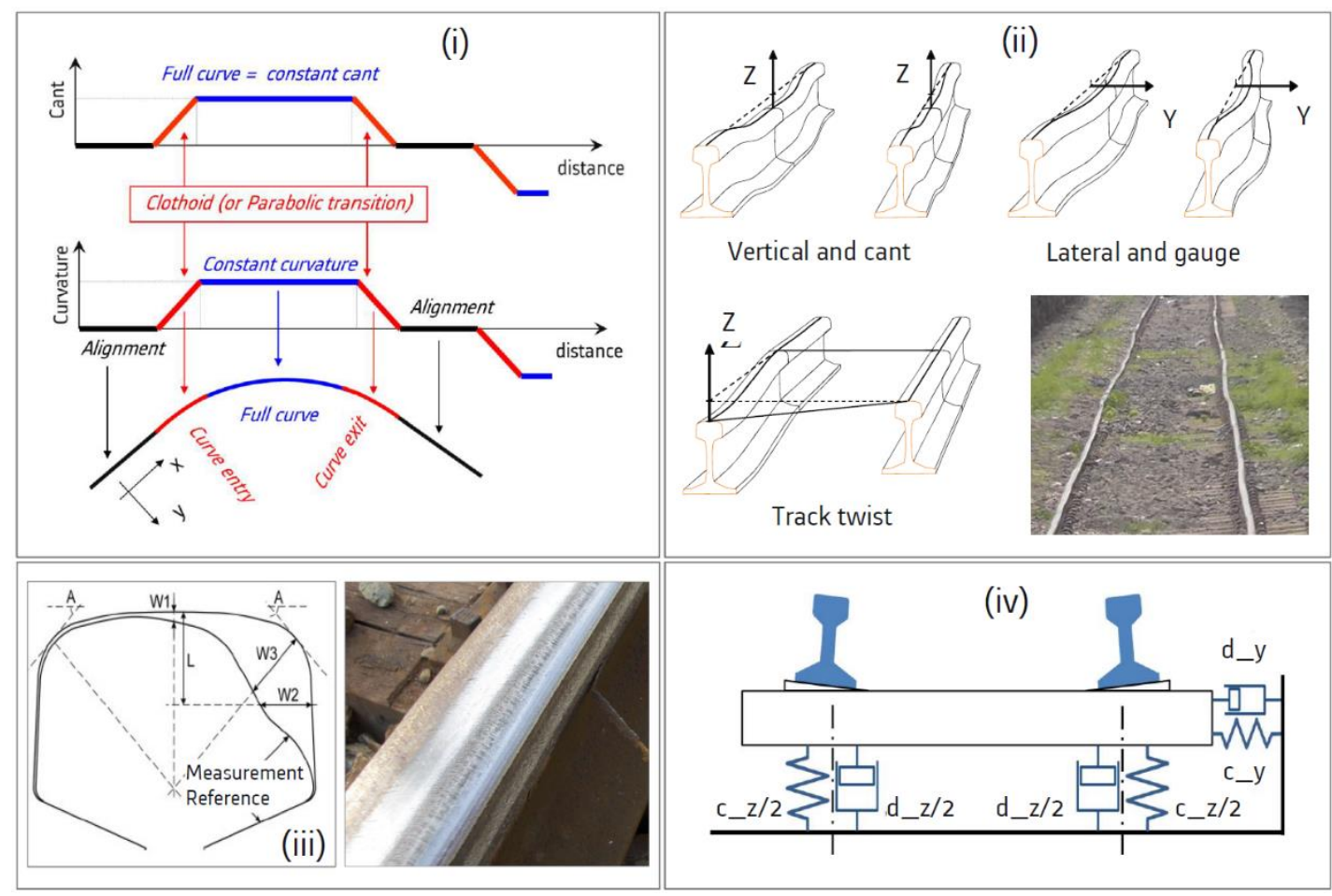

Figure 2: (i) Track layout, (ii) track irregularities (iii) rail profiles (iv) track stiffnes/damping

\subsection{Identification of Relevant Case Studies}

In [1], the attention was mainly devoted to the impact that the maintenance conditions of the vehicle components can have on the loads transmitted to the infrastructure. Now, the study is enlarged by analysing the consequences of the maintenance state of the track on the vehicle components.

Dynamic studies can help to identify all the track features that have significant impact on the track and vehicle loads. Nevertheless, a preliminary analysis and selection of the key components/parameters to be considered is the first challenge in creating reliable simulation scenarios. The aspects of the track related to the contact conditions, such as the track layout, track irregularities and rail profiles, that can have a meaningful influence on the dynamics of the vehicle and, consequently, on the loads and on the wear in general, are analysed here.

First of all, an attempt is made to discriminate the effect of irregularities and the construction characteristics of the track from the effect of wear of the rail profile on the dynamic behaviour of the train and on the track damage. The application of the criteria required by the normative related to running safety, ride quality and track fatigue, assessed on a case-by-case basis, allow to evaluate if the loads are more impacting the vehicle's or the track's damage. The interested reader can find more details in references $[1,71,95,96]$. In the following some examples of impact analysis are provided.

As the aim of this work is to analyse the variation of vehicle-track loads as a function of the track parameters, the assessment quantities considered here are: 
- The track loads, i.e., track shift forces and the vertical wheel-rail loads according to EN 14363 [85];

- The track damage.

Figure 3 highlights, qualitatively, the different impact that the three main types of track parameters, i.e. track geometry, rail profiles and track design, can have on the analyzed output.

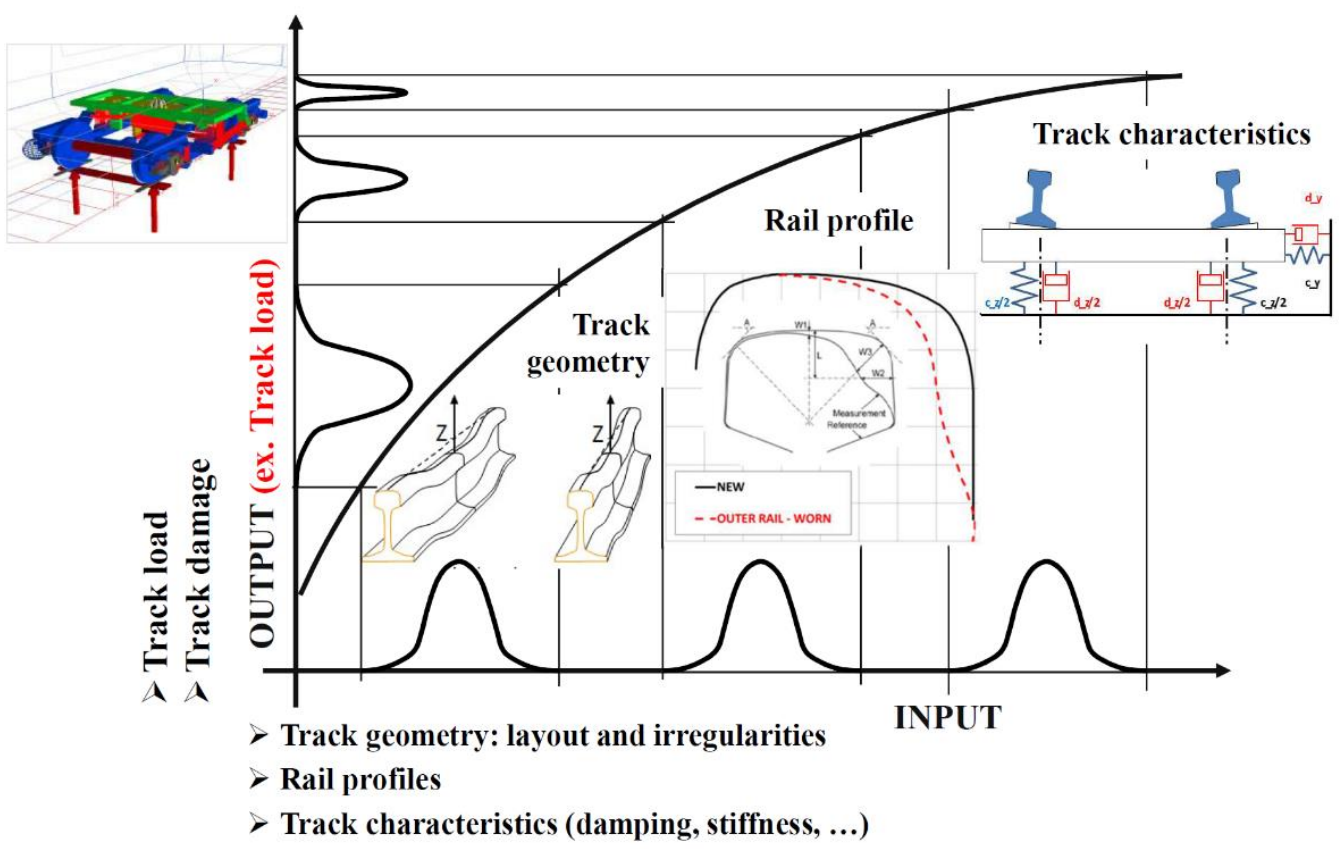

Figure 3: Approach for the identification of parameters impact on running behaviour

Each parameter can vary in a certain range of values, with a consequent effect on the outputs considered. For example, the figure shows that the geometry of the track and the state of wear of the tracks affect more than the elasticity of the track itself, which can vary depending on whether it is made by wooden or concrete sleepers or on the maintenance status of the track substructure.

Therefore, in order to obtain a reliable evaluation of the track loads, it will be necessary to model the real track layout, the measured irregularities and the measured rail profiles, while the track stiffness and damping values used could be those proposed by default by the MB codes, or scaled values, based on best practises and field experience.

\section{Studies on the Maintenance Conditions of the Track}

To correctly design a railway vehicle, the operating condition of the train shall be specified, including the maximum speed, the minimum radius curve (reverse curve), the maximum cant and maximum cant deficiency, and the following track characteristics:

- Track gauge (including any variation due to track widening in small curves);

- Rail head profile (new and typical worn); 
- Inclination of the rail;

- Track twist;

- Track quality (track geometry deviation relative to line speed).

Other parameters, like the vertical stiffness and damping of the track or the rail material, that can have a direct effect on the wheel-rail contact forces, in different frequency ranges, are out of the scope of this study.

The focus here is on the impact on the track loads generated considering three main groups of characteristics: (i) the macro-geometry or track layout; (ii) the microgeometry or track irregularities; (iii) construction parameters like the rail head profile.

\subsection{Track Layout or Macro-Geometry}

The railway tracks are made, in the horizontal plane, of alignement elements with infinite radius (straight track), constant radius (circular curve) or variable radius (transition curve between straight track and circular curve), as schematically illustrated in Figure 2 (i). In the vertical plane, each alignement element can have a vertical curvature, while the cant is the amount by which one running rail is raised above the other, to partially compensate the centrifugal force applied on a vehicle running at a certain speed in curve.

Figure 4 shows an example of the track macro-geometry inputs for simulation in SIMPACK: (i) a cartographic plane view of the line (layout); (ii) the curvature variation along the line, as inverse of the radius, so that in straight track the curvature is equal to zero, and; (iii) the corresponding cant in curve. 

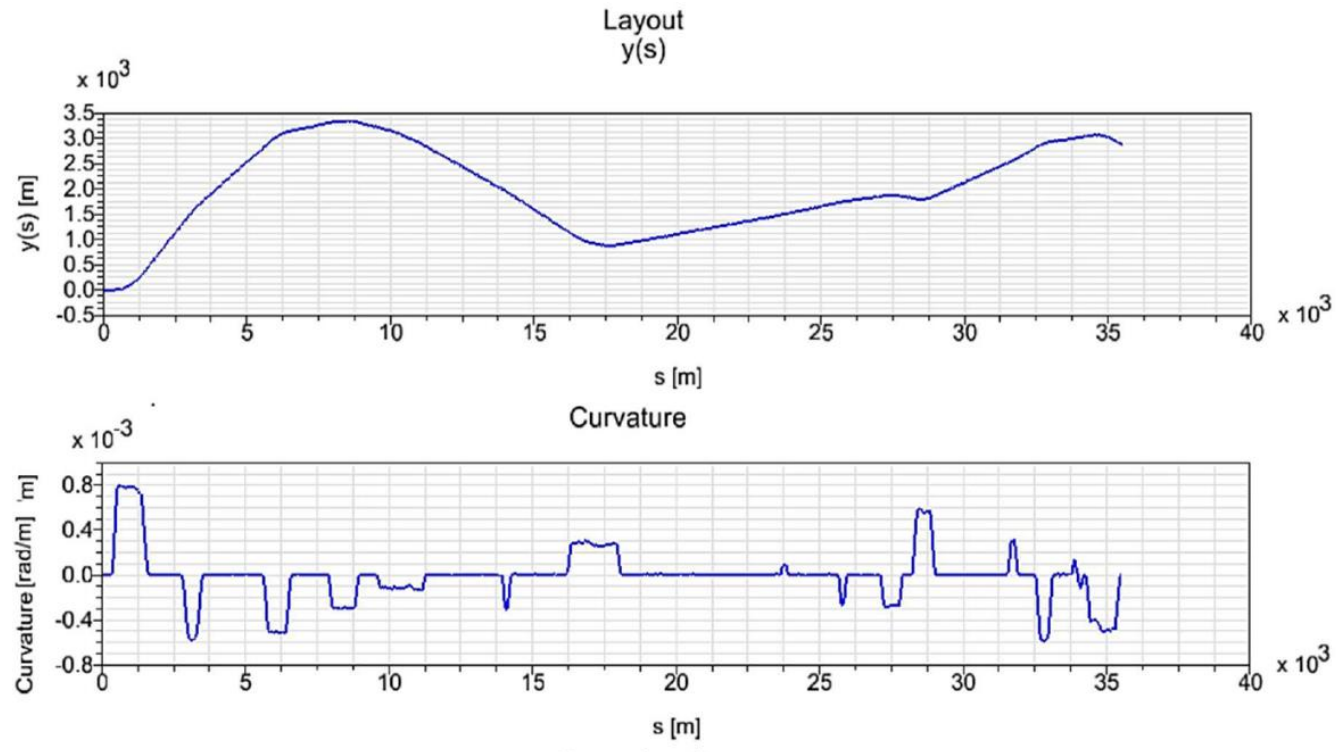

Superelevation

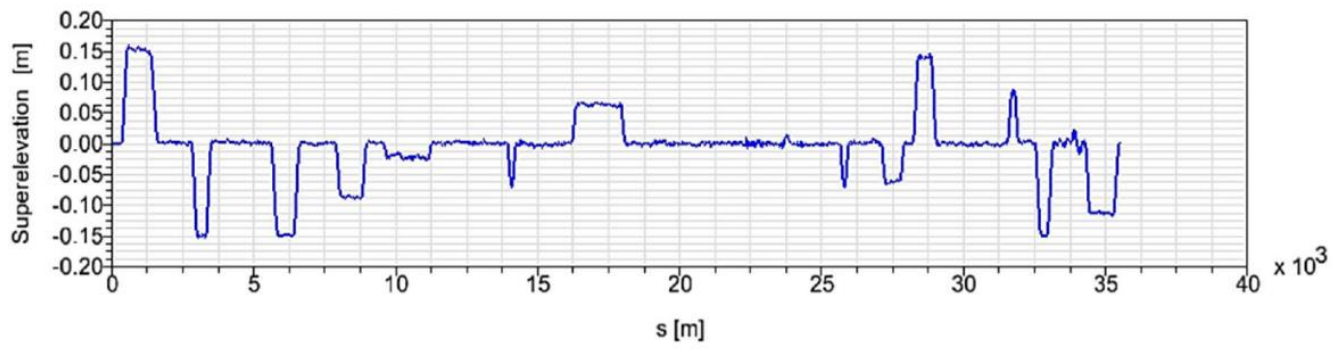

Figure 4: Model of track macro-geometry in MB environment

The wheel-rail forces in curve are influenced by the geometry of the curve and by the running speed, that together give rise to the lateral acceleration at track level, not compensated by the track cant, usually called Non-Compensated Acceleration (NCA), with the following expression:

$$
\mathrm{NCA}=\mathrm{V}^{2} / \mathrm{R} \cdot \cos \beta-\mathrm{g} \cdot \sin \beta \approx \mathrm{V}^{2} / \mathrm{R}-\mathrm{g} \cdot \mathrm{h} / \mathrm{b} \quad\left[\mathrm{m} / \mathrm{s}^{2}\right]
$$

where V $(\mathrm{m} / \mathrm{s})$ is the train speed, $\mathrm{R}(\mathrm{m})$ is the curve radius, $\mathrm{g}\left(\mathrm{m} / \mathrm{s}^{2}\right)$ is the constant of gravity, $\mathrm{h}(\mathrm{mm})$ is the cant in curve, $\mathrm{b}(\mathrm{mm})$ is the distance between the contact points of the wheels on the rails and $\beta$ is the track angle, as shown in Figure 5. 


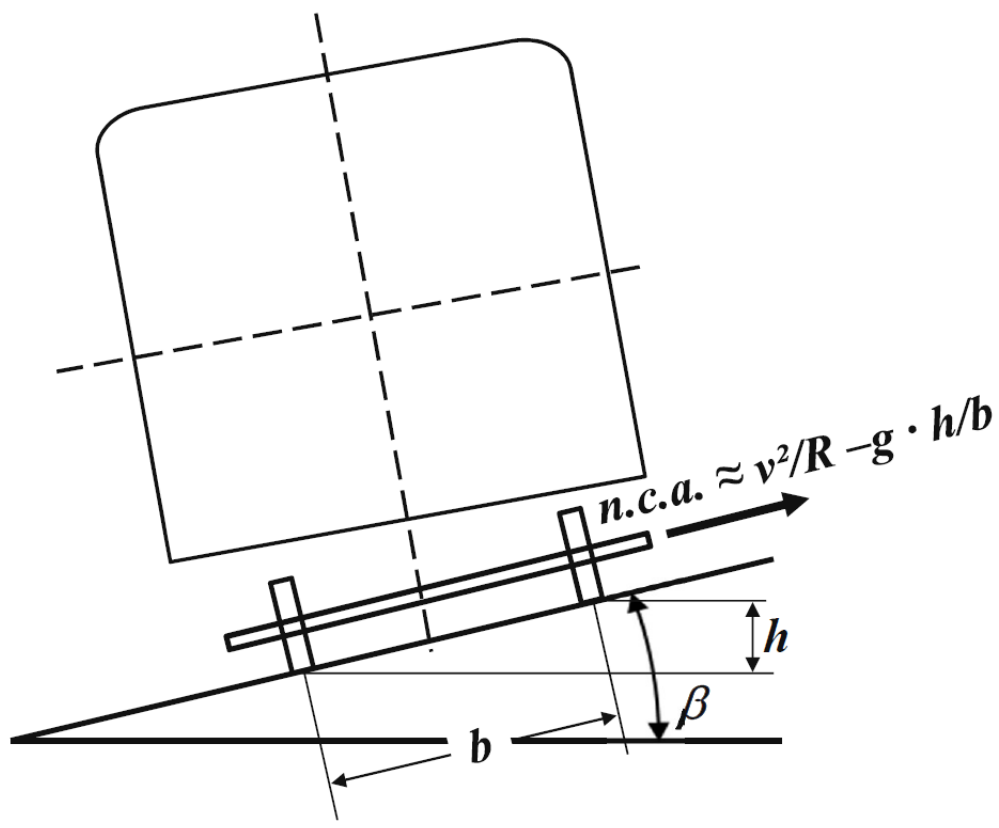

Figure 5: NCA definition

The cant deficiency (CD), a quantity commonly used in railway for practical reasons, is the amount of rail cant missing to annul the NCA and is given by:

$$
\mathrm{CD}=\mathrm{NCA} \cdot \mathrm{b} / \mathrm{g} \quad[\mathrm{mm}]
$$

In the ideal case of a single wheelset running in a curve with $\mathrm{CD}$, the quasi-static track shift forces $\left(\Sigma \mathrm{Y}_{\mathrm{qst}}\right)$, i.e the sum of lateral forces acting on the two wheels, is mainly function of the axleload and of the CD.

In real bogies, when running with a costant $C D$ in all the curves (e.g. $C D=150$ $\mathrm{mm}$ ), the mean value of the $\Sigma \mathrm{Y}_{\mathrm{qst}}$ on the two wheelsets is costant, but normally not equally distributed between the two wheelsets, as shown in Figure 6 (left ). The quantity on the first wheelset (WS1) and on the second (WS2) depends also on the design chracteristics of the vehicle and varies as function of the radius of the curve. By increasing the cant deficiency in the same curves (e.g. $\mathrm{CD}=300 \mathrm{~mm}$ ), typical of a tilting train, not only an increase in forces is observed but a still different distribution according to the curve radius, as shown in the same figure (full lines in comparison to dotted lines). Finally, a further contribution to the wheel-rail contact forces is due to the track defects (dynamic effect), as it will be shown better below, depending, to a varying extent, from the speed, $C D$ and dynamic properties of the vehicle. In Figure 6 (right) the two bars, as function of the $\mathrm{CD}$, give an idea of the different component of $\Sigma Y_{\text {max. }}$ The mean quasi-static part due mainly to the $C D$, a certain scatter due to the radius of the curves and the dynamic effect due to the track irregularities. 

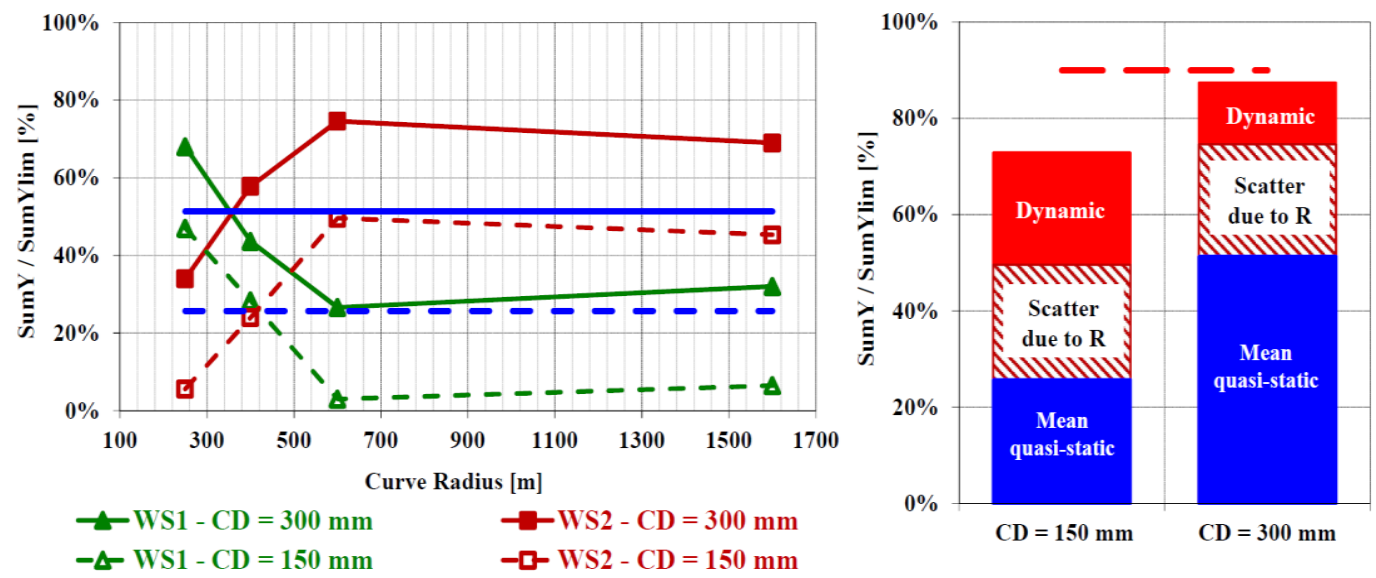

Figure 6: Variation of $\Sigma \mathrm{Y}_{\mathrm{qs}} / \Sigma \mathrm{Y}_{\text {lim }}$ in function of curve radius (left); Contributions to track shift force $\Sigma Y_{\max }$ (right)

As regards the maximum values of the forces that govern the running safety, and of the loads exchanged between the vehicle and the track, other parameters such as the Rate of Change of Cant (related to the length and gradients of the transition curves), as the track stiffness and damping values, as the transitions between open track and tunnel/bridges, should be taken into account.

The macro-geometry is therefore important and should be well known in the design

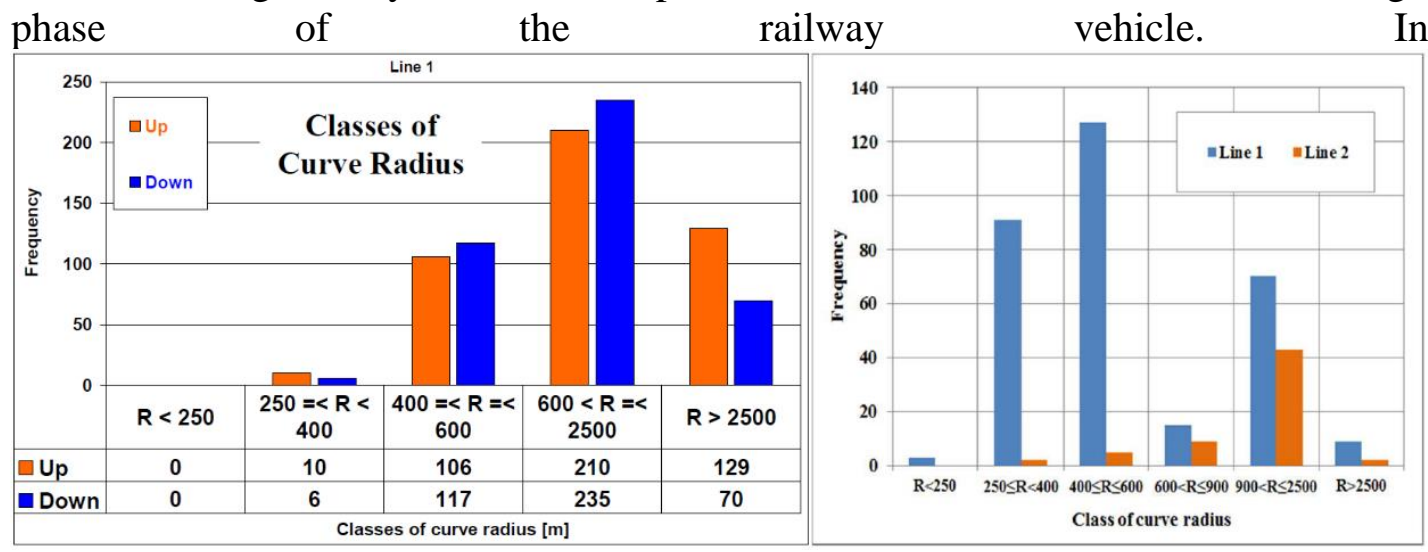
vehicle.

In

Figure 7 (left) an example of analysis of a service line, about $500 \mathrm{~km}$ long, in the two running directions, considering the classes of curve radius is shown.

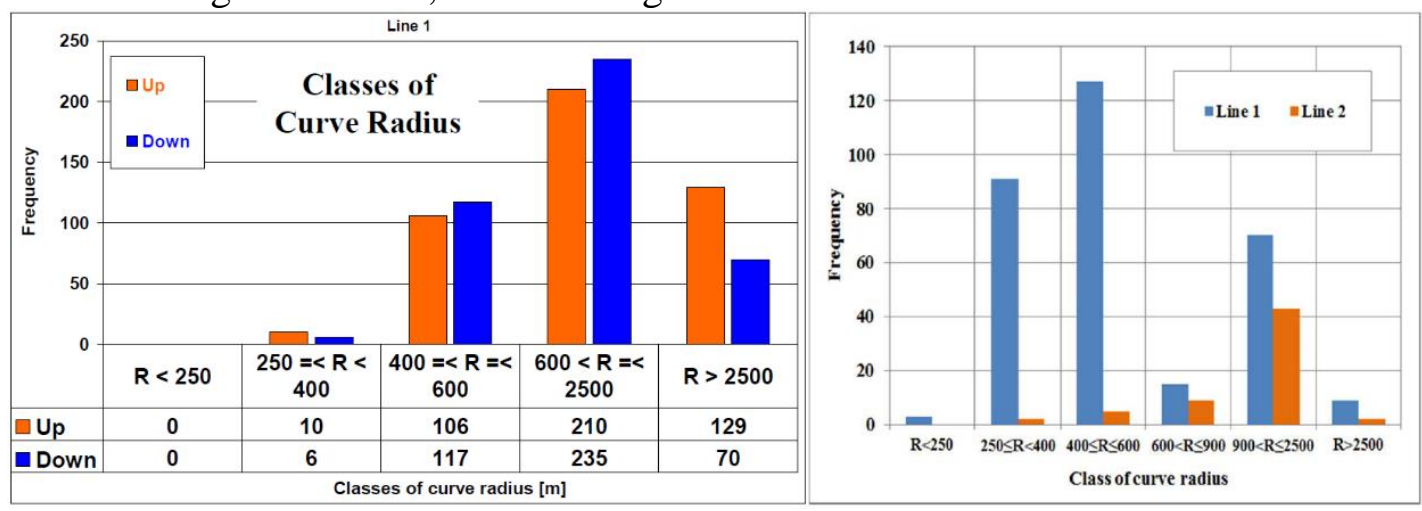


Figure 7 (right) the same type of analysis has been made on two different lines, dedicated to regional service, but with a quite different distribution of curves.
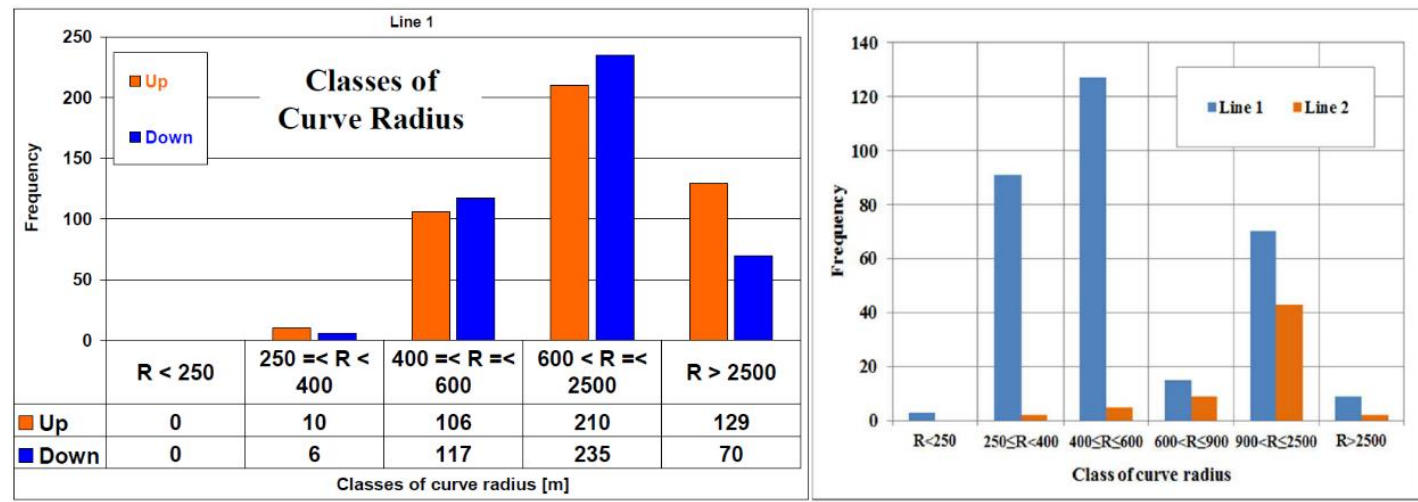

Figure 7: Examples of macro-geometry analysis - curve radii classification and distribution

In similar way, also other geometric parameters, like the cant in curve or the transition slope, can be analysed and a correlation between the track layout and the vehicle-track echanged forces can be defined.

\subsection{Track Irregularities or Micro-Geometry}

Track irregularities or defects, named also as track micro-geometry, are deviations from the average value or from the design value of some geometric parameters of the track, defined in the vertical or horizontal plane, related to safety and ride quality. Their classification in different levels is known as analysis of the the track geometry quality.

The track irregularities that characterise the state of maintenance of a track, are evaluated in terms of:

- Type: longitudinal level, alignment, cross level, track gauge, twist, as shown in Figure 2 (ii);

- Amplitude of each defect;

- Wavelength $(\lambda)$ content of each defect.

For the railway dynamic studies, wavelengths greater than $1 \mathrm{~m}$ are usually considered, while typical range for the track quality assessment, according to EN 13848-1 [97], are $3 \mathrm{~m}<\lambda \leq 5 \mathrm{~m}, 25 \mathrm{~m}<\lambda \leq 70 \mathrm{~m}$ and, for line speeds greater than $250 \mathrm{~km} / \mathrm{h}, 70 \mathrm{~m}<\lambda \leq 150 \mathrm{~m}$ for longitudinal level and $70 \mathrm{~m}<\lambda \leq 200 \mathrm{~m}$ for alignment.

Figure 8 shows an example of the track micro-geometry inputs for simulation in SIMPACK. The measured irregularities (lateral, vertical, cross level and track gauge) are analysed in terms of Power Spectral Density, in function of the spatial frequency, which is useful to identify the wavelength content of the measured data and, consequently, the exciting frequencies in function of the running speed. 


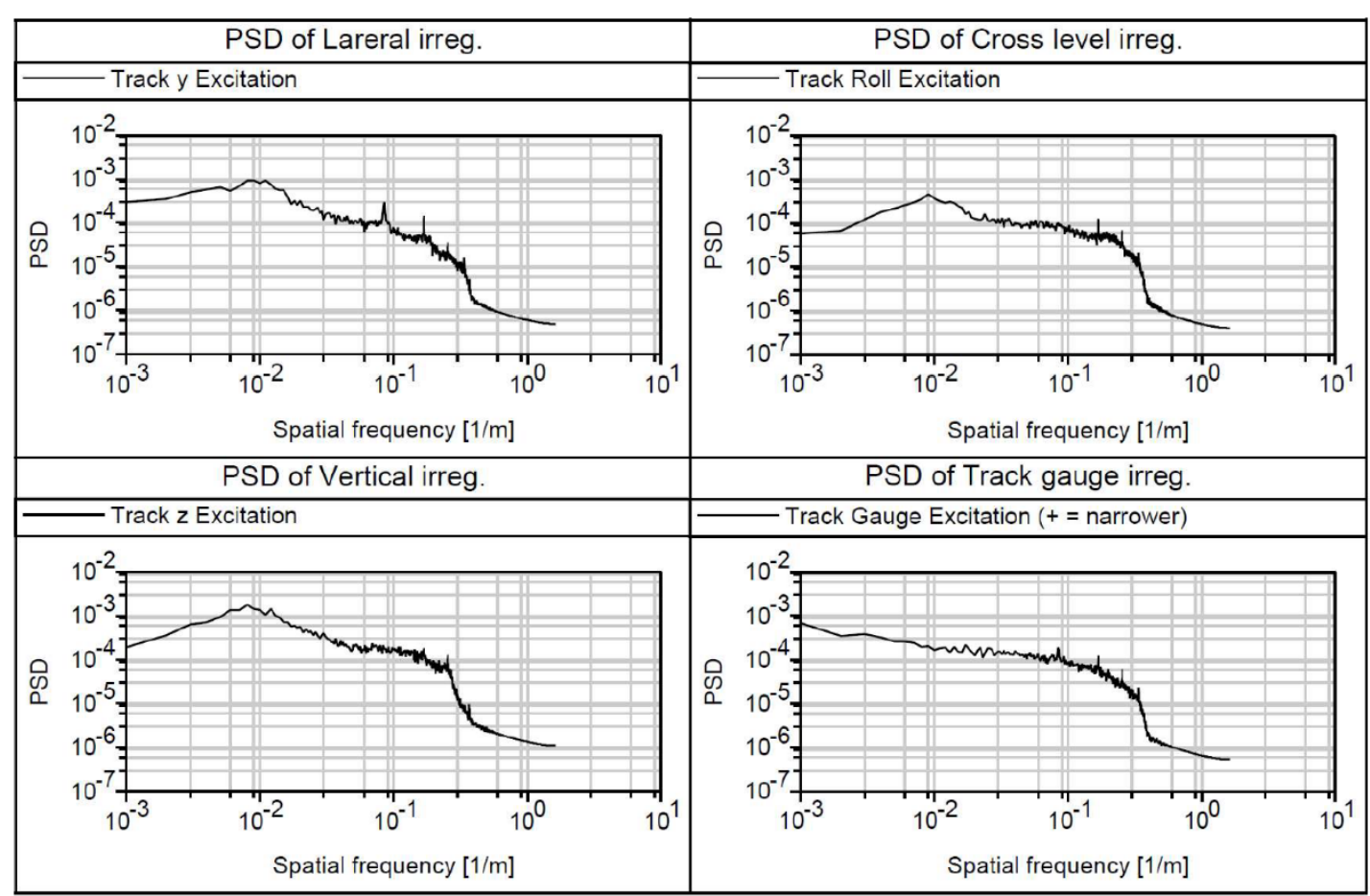

Figure 8: Analysis of wavelength content through Power Spectral Density function

The international standards and the directives of the railway administrations use the standard deviation or the peak values of the measured irregularities to judge the status of maintenance of the track. The EN 13848-5 [98] defines three levels of track conditions to which correspond actions of maintenance:

- Immediate Action Limit (IAL): Refers to the value which, if exceeded, leads to the infrastructure manager taking measures to reduce the risk of derailment to an acceptable level. This can be done either by closing the line, reducing speed or by correcting the track geometry.

- Intervention Limit (IL): Refers to the value, which, if exceeded, requires corrective maintenance in order that the immediate action limit shall not be reached before the next inspection.

- Alert Limit (AL): Refers to the value which, if exceeded, requires that the track geometry condition is analysed and considered in the regularly planned maintenance operations.

Thus, the infrastructure manager can assess the status of maintenance of the track by measuring the track irregularities and comparing the results with the limits of the following parameters:

- Lateral alignment: standard deviations (alert limit only)

- Longitudinal level: standard deviations (alert limit only)

- Lateral alignment (isolated defects): mean to peak values

- Longitudinal level (isolated defects): mean to peak values

- Track twist (isolated defects): zero to peak value

- Variation of gauge (isolated defects): nominal gauge to peak value

- Mean track gauge over any $100 \mathrm{~m}$ length: nominal gauge to mean value 
The track quality is determined by the presence of the above defects with certain amplitudes that are repeated with several wavelengths.

To understand the effect of a single defect, let's consider the simple model illustrated in figure 9 consisting of a single wheelset, connected to a body of mass $\mathrm{M}$ through a suspension stage, which advances with speed $\mathrm{V}$ on a sinusoidal irregularity of amplitude A and wavelength $\lambda$. The simple equation that determines the variation of vertical force $\mathrm{P}$ at the wheel-rail contact is the following:

$$
\mathrm{P}=\mathrm{P}_{0}-\left(\mathrm{m}_{0} / 2\right) \cdot \mathrm{a}_{\mathrm{z}}
$$

where $\mathrm{P}_{0}$ is the vertical load at the wheel-rail contact point, $\mathrm{m}_{0}$ is the mass of the wheelset and $\mathrm{a}_{\mathrm{z}}$ the vertical acceleration of the suspended mass, directly proportional to the square of the speed $\mathrm{V}$ and the amplitude $\mathrm{A}$ and inversely proportional to the square of the wavelength $\lambda$. Therefore the vertical load $\mathrm{P}_{0}$ and the related wheel unloading $\Delta \mathrm{P} / \mathrm{P}_{0}$, linked with overturning and derailment phenomena, depends not only by the speed but also by the shape of the track defects. In Figure 9 on the right at the top and bottom, on graphs with double-axis of the ordinates, the vertical acceleration and the wheel unloading $\Delta \mathrm{P} / \mathrm{P}_{0}$ with its limit are diagramed: at the top, keeping the speed constant, as the wavelength of the defect changes; at the bottom, on the contrary, by setting a certain wavelength and by making the speed vary.

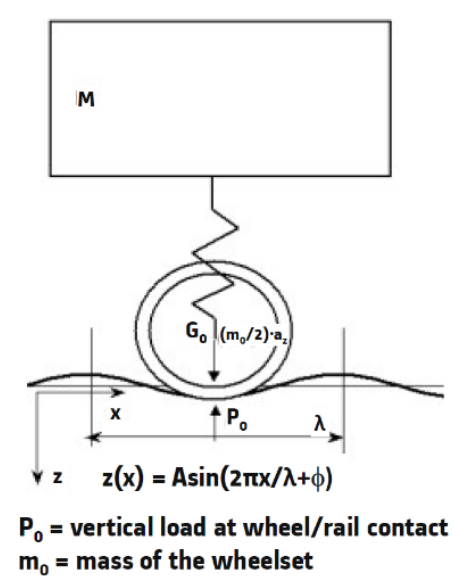

Simple mass-spring model to study impact of isolated track irregularities on vertical vehicle-track loads
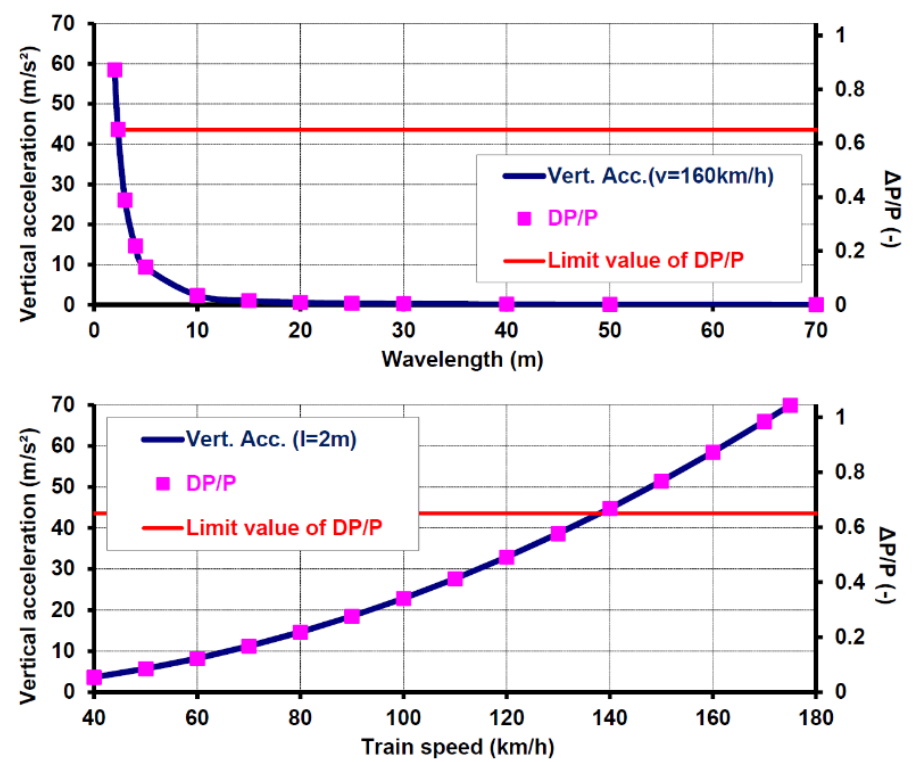

Figure 9: Simple model of track excitation (left); Vertical maximum acceleration and $\Delta \mathrm{P} / \mathrm{P}_{0}$ vs. wavelength at constant speed (right up); Vertical maximum acceleration and $\Delta \mathrm{P} / \mathrm{P}_{0}$ vs. speed at constant wavelength (right down)

It is evident that the running speed and the shape of the defect, characterised by amplitude and wavelength, are of great concern in determining the vehicle response to track irregularities.

Moving from the simple model to the complex model that considers the combination of multiple defects, Figure 10 on the left shows an example of how the 
wheel unloading $\left(\Delta \mathrm{P} / \mathrm{P}_{0}\right)$ increases when the track excitation is composed of multiple components. The graph in Figure 10 on the right shows how the vertical acceleration of the wheel, due to the combination of track irregularities, is amplified by about 15$20 \%$ (in the example considered) compared to the acceleration caused by the single vertical irregularity.
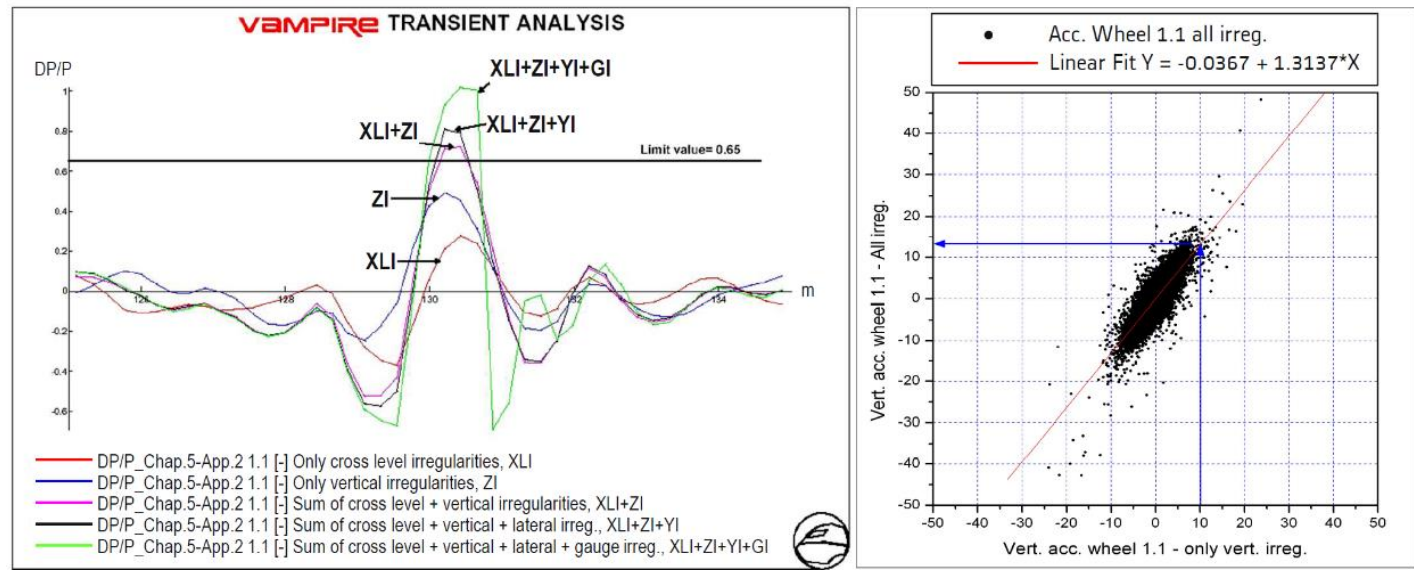

Figure 10: Combined track irregularities: Effect on $\Delta \mathrm{P} / \mathrm{P}_{0}$ (left), Effect on vertical acceleration of the wheel (right)

When considering all the track irregularities, the amplitude and the wavelength $(\lambda)$ (or the spatial frequency $(1 / \lambda)$ ) contents are very important in determining the vehicle behaviour. To study the effect of different amplitudes, simulations with the same model, changing only the track irregularities amplitude by a scaling factor are performed. For this type of analyses, the use of theoretical irregularities, like the small and big defects defined in ORE B176 Rp1 Annexe 6 [99], and shown in Figure 11, is more appropriate than the measured data. In the following plots, red and green curves indicate results for big and small defects, respectively.

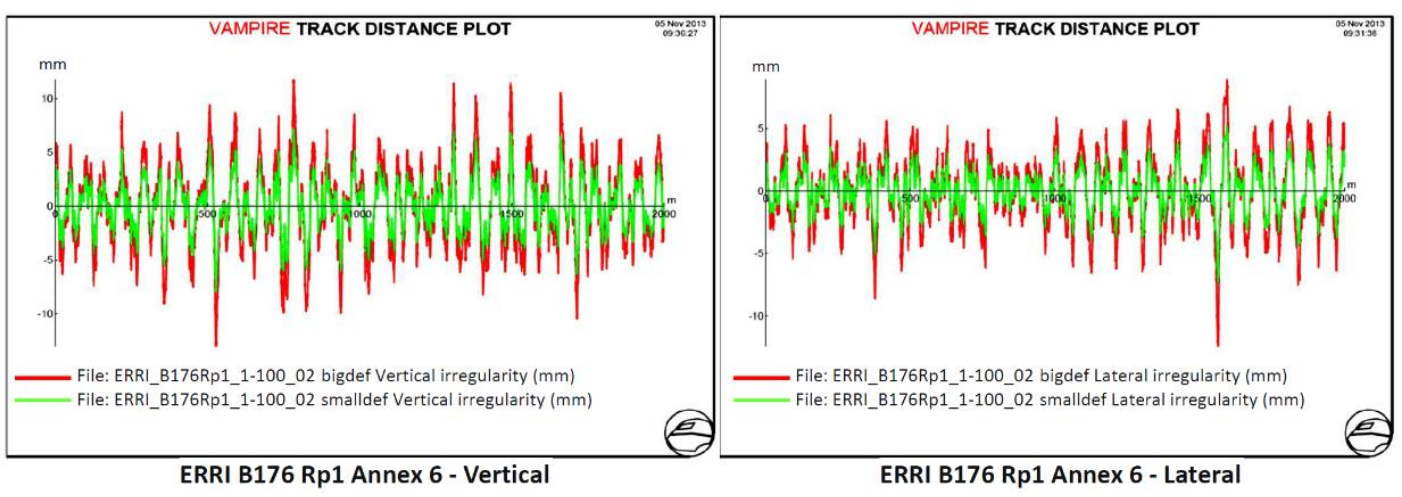

Figure 11: ERRI B176 Rp1 Annex 6 small and big defects comparison: Space history of vertical defect (left), Space history of lateral defect (right)

The simulation results of the same vehicle model, running on the tracks with two levels of irregularities, can be compared to assess the influence of the different defect 
amplitudes. Figure 12 compares the space history of the bogie and carbody accelerations, while the PSD analysis of the same signals is compared in Figure 13.
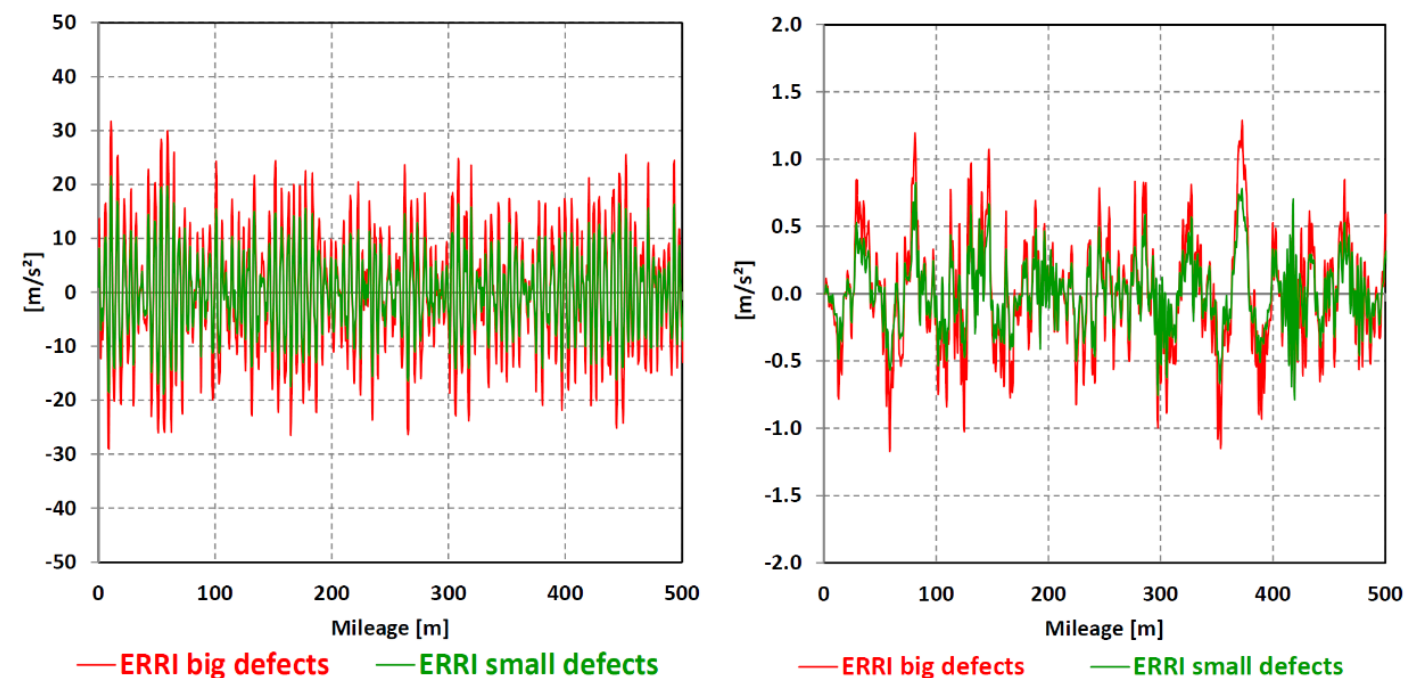

Figure 12: Space history of vertical accelerationson: Bogie (left); Carbody (right)
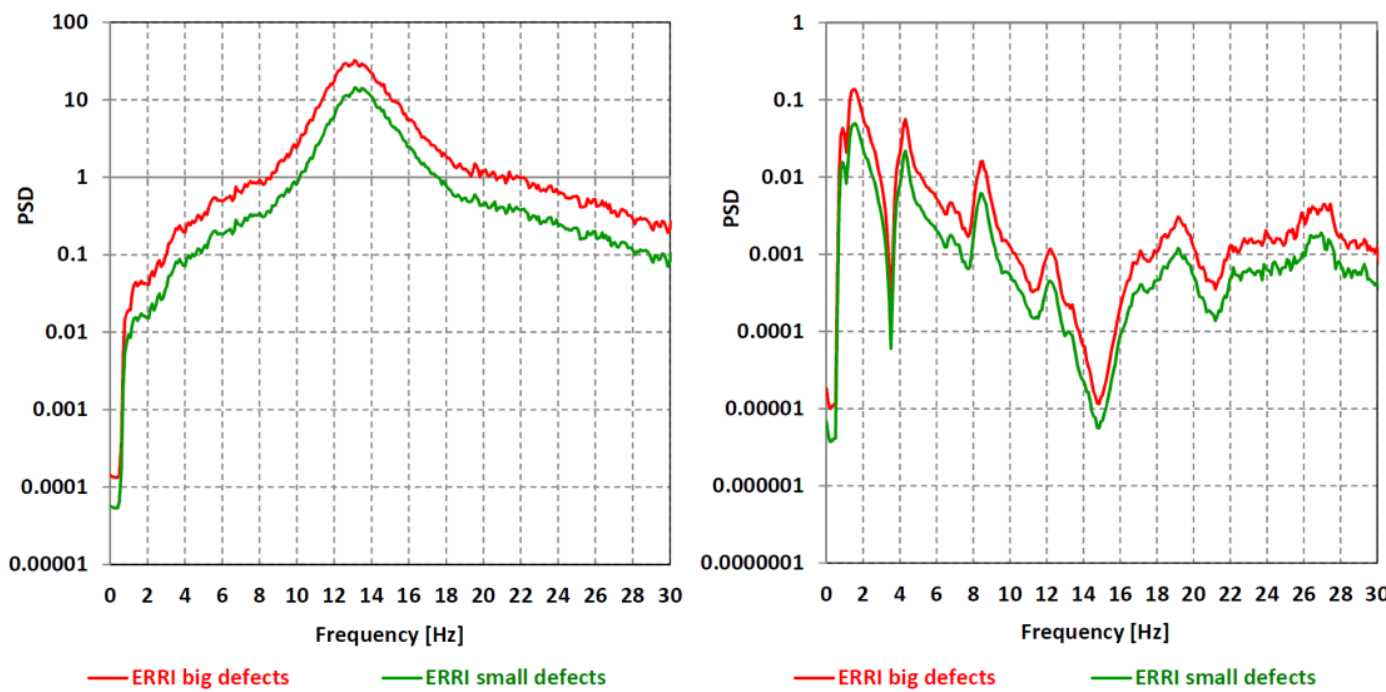

Figure 13: PSD of vertical accelerations: Bogie (left); Carbody (right)

These simulations are performed with an high speed train with flexible carbody running at $250 \mathrm{~km} / \mathrm{h}$. The same type of analyses can be done for lateral accelerations.

Accelerations and forces generated on the wheel/rail contact are transferred from the contact point to the different vehicle components and sub-systems. Figure 14 shows the response, to track excitation, of the wheelset (non-suspended mass), of the bogie (one level of suspension) and of the carbody (two levels of suspension). The typical frequency ranges of primary and secondary suspensions are highlighted in the dot-line rectangles, while the red rectangle put in evidence a range of frequencies 
associated with the resonance of flexible modes of the carbody. It is observed that the level of vibrations on different parts of the vehicle and of the suspended equipments, varies in function of the frequency and of the track excitation.

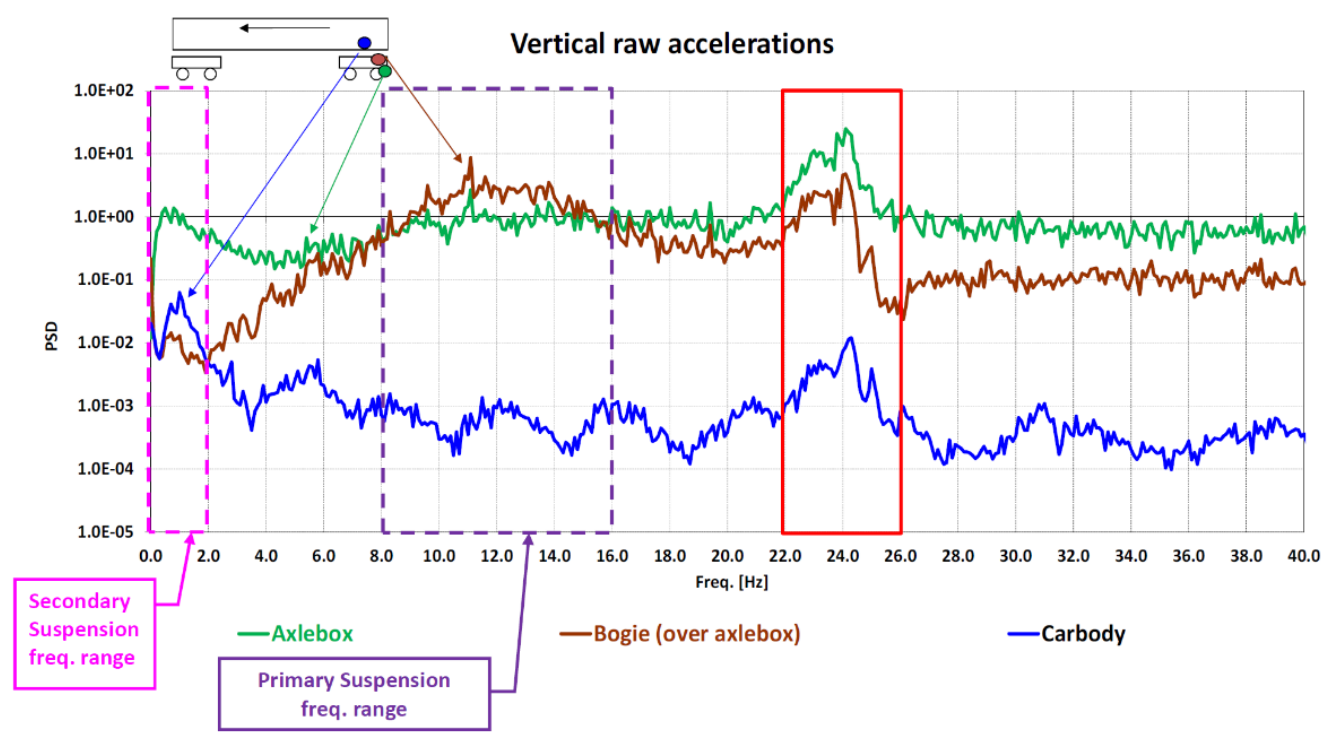

Figure 14: Frequency response to track excitation from axlebox to carbody structure

It is observed that the loads on the vehicle depend on the track excitation amplitudes and frequencies, on the different level of suspension of the detecting points, on the natural frequencies of the system and on the running speed. Moreover, the propagation of the vibrations on the vehicle induced by the track irregularities demonstrate that, in some cases, the filtering effect of the vehicle suspensions can be partly by-passed or even that the response of the vehicle-track system can be amplified with respect to the initial excitation.

\subsection{Rail Profiles and Equivalent Conicity}

Another indication of the maintenance status of the track is given by the wear of the rail profile, an example of which is shown in the upper part of figure 15 . The variation in the shape of the profile, with different patterns on the inner (lower) rail and the outer (higher) rail, modifies the geometry of the wheel-rail contact and consequently the dynamics of the vehicle and in particular the loads on the vehicle an on the track. A derived and synthetic parameter for the evaluation of the conditions of the wheelrail contact is the equivalent conicity $\gamma_{\mathrm{eq}}$.

Figure 15 (top) shows the difference of between new (red) and worn (blue) rail profiles in a measured section of a curve and Figure 15 (down-left) the consequent equivalent conicity $\gamma_{\mathrm{eq}}$ calculated with new S1002 wheel profile.

The effect of the two contact conditions on the track-shift forces is shown in Figure 15 (down-right), through the Power Spectral Density analysis of the track-shift forces: the higher level of track-shift forces in case of worn rails, that is to say in case of higher equivalent conicity, is much evident. Therefore the maintenance status of the 
rails and the equivalent conicity in service shall be monitored, to ensure safe operations and to limit as much as possible the dynamic loads.

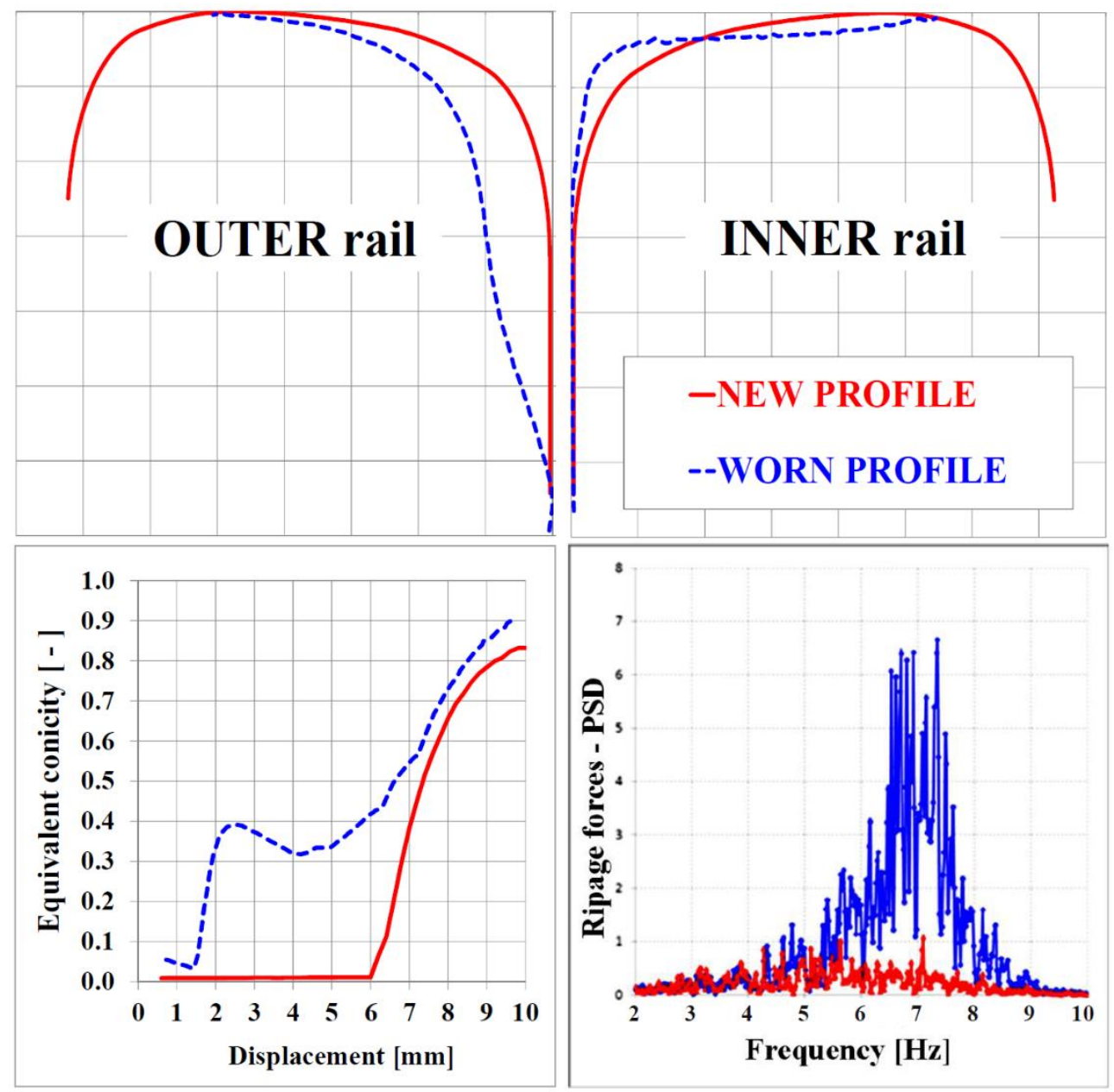

Figure 15: New and worn rail profiles patterns (top); Equivalent conicity $\gamma_{\mathrm{eq}}$ function (down-left); Track-shift forces analysis PSD (down-right)

\section{Conclusions and Further Developments}

The track degradation shall be kept under control to minimise safety risks and operational costs. This work analyses the influence of different states of track maintenance on vehicle-track loads and on the dynamic behaviour of the rail vehicles.

The track geometry, track design characteristics and wear of rail profiles are important factors in the design and life cycle cost of the rolling stock. The results presented here allow to conclude:

- The track layout is a key parameter affecting the wheel-rail contact loads and their distribution on different wheelsets and consequently the wheel-rail wear and profile evolution. Therefore, it should be known since the beginning and taken into account for the vehicle design optimization. 
- The track quality, seen as amplitude and wavelength of the track irregularities on the inner and outer rail, is the main source of the vibrations and shocks acting on vehicle and track parts. Their frequencies are related with the irregularity wavelength and the running speed, while the amplitude of the accelerations and loads depends on the amplitude of the irregularities, together with the proper frequency and inertia of the vibrating components.

- The condition of degradation of the rails causes a significant increase in the loads exchanged between the vehicle and the track. Track maintenance criteria are therefore a key factor in minimizing safety risks and operating costs, both for the infrastructure managers and the service providers.

For all these reasons, the analyses presented in this work are important but need to consider the real health state of the track components and the service tolerances allowed for the various parameters of the track sub-system.

Future steps in this work should go towards (i) the enhancement of the vehicle MB models for the simulation of the vehicle-track response in the whole range of the frequencies of interest, and; (ii) the extension of the methodology proposed here to determine the loads mission profile on the vehicle parts and on the mounted equipments.

\section{Acknowledgements}

This work has been possible thanks to the support of ALSTOM experts, who have been working for many years on the study, development, design and manufacturing of all types of trains. The contribution of J. Pombo to this work was supported by FCT, through IDMEC, under LAETA, project UIDB/50022/2020.

\section{Declaration of Conflicting Interests}

The authors declared no potential conflicts of interest with respect to the research, authorship, and/or publication of this article.

\section{Funding}

The authors received no financial support for the research, authorship, and/or publication of this article.

\section{ORCID iD}

Naim Kuka: 0000-0002-0707-0445

João Pombo: 0000-0002-5877-1989

\section{References}

[1] Kuka N, Verardi R, Ariaudo C, Pombo J. Impact of maintenance conditions of vehicle components on the vehicle-track interaction loads. Proc Inst Mech Eng Part C J Mech Eng Sci 2018;232:2626-41. doi:10.1177/0954406217722803.

[2] Piao MW, Liang SL, Wei HL, Fang J, Zhao WZ. Novel Stability Theory based on Absorbing-Band Anti-Hunting Mechanism of High-Speed Bogies. 
Int J Railw Technol 2013;2:1-33. doi:10.4203/ijrt.2.2.1.

[3] Pei SY, Wang HS, Xi H, Wang HY, Chang W, Wei H, et al. Contact Performance of an Axle Bearing Assembly under Impact and Vibration Conditions of the Wheel-Flat and Rail-Gap of a Railway Passenger Train. Int J Railw Technol 2016;5:53-81. doi:10.4203/ijrt.5.1.3.

[4] Magalhães H, Marques F, Liu B, Antunes P, Pombo J, Flores P, et al. Implementation of a non-Hertzian contact model for railway dynamic application. Multibody Syst Dyn 2019. doi:10.1007/s11044-019-09688-y.

[5] Pugi L, Conti R, Nocciolini D, Galardi E, Meli E. A Comprehensive Tool for the Optimization of Traction and Braking systems with respect to the Application of Energy Storage devices. Int J Railw Technol 2015;4:69-93. doi:10.4203/ijrt.4.1.4.

[6] Polach O, Evans J. Simulations of Running Dynamics for Vehicle Acceptance: Application and Validation. Int J Railw Technol 2013;2:59-84. doi:10.4203/ijrt.2.4.4.

[7] Polach O, Böttcher A, Vannucci D, Sima J, Schelle H, Chollet H, et al. Validation of simulation models in the context of railway vehicle acceptance. Proc Inst Mech Eng Part F J Rail Rapid Transit 2015;229:729-54. doi:10.1177/0954409714554275.

[8] Magalhães H, Madeira JFA, Ambrósio J, Pombo J. Railway vehicle performance optimisation using virtual homologation. Veh Syst Dyn 2016;54:1177-207. doi:10.1080/00423114.2016.1196821.

[9] Magalhães H, Pombo J, Ambrósio J, Madeira JFA. Rail vehicle design optimization for operation in a mountainous railway track. Innov Infrastruct Solut 2017;2. doi:10.1007/s41062-017-0088-1.

[10] Xiao X, Jin X, Deng Y, Zhou Z. Effect of curved track support failure on vehicle derailment. Veh Syst Dyn 2008;46:1029-59. doi:10.1080/00423110701689602.

[11] Sunami H, Termichi Y, Adachi M. An Analytical Study of Derailed Vehicle Motion from Wheel-Sleeper Impacts. Int J Railw Technol 2013;2:35-63. doi:10.4203/ijrt.2.2.2.

[12] Pascal JP. Reliability of High Speed Dynamical Derailment Simulations. Int J Railw Technol 2014;3:41-54. doi:10.4203/ijrt.3.3.3.

[13] Matsumoto A, Michitsuji Y, Tobita Y. Analysis of Train-Overturn Derailments caused by Excessive Curving Speed. Int J Railw Technol 2016;5:27-45. doi:10.4203/ijrt.5.2.2.

[14] Terumichi Y. Modelling of Railway Vehicle Motion during Large Earthquakes. Int J Railw Technol 2016;5:65-89. doi:10.4203/ijrt.5.2.4.

[15] Tanabe M, Sogabe M, Wakui H, Rose JG. Interaction of High-Speed Train and Railway Structure during an Earthquakes. Int J Railw Technol 2017;6:25-38. doi:10.4203/ijrt.6.2.2.

[16] Teng W, Shi H, Luo R, Zeng J, Huang C. Improved nonlinear model of a yaw damper for simulating the dynamics of a high-speed train. Proc Inst Mech Eng Part F J Rail Rapid Transit 2019;233:651-65. doi:10.1177/0954409718804414.

[17] Qazizadeh A, Persson R, Stichel S. Preparation and Execution of On-track 
Tests with Active Vertical Secondary Suspension. Int J Railw Technol 2015;4:29-46. doi:10.4203/ijrt.4.1.2.

[18] Bruni S, Vinolas J, Berg M, Polach O, Stichel S. Modelling of suspension components in a rail vehicle dynamics context. Veh Syst Dyn 2011;49:102172. doi:10.1080/00423114.2011.586430.

[19] Pombo J, Ambrósio J. Modelling tracks for roller coaster dynamics. Int J Veh Des 2007;45:470. doi:10.1504/IJVD.2007.014916.

[20] Sequeira B, Pombo J, Antunes P, Ambrósio J, Woodward P. Construction of Three-Dimensional Track Models for Roller-Coaster Applications. CivilComp Proc., vol. 110, 2016. doi:10.4203/ccp.110.99.

[21] Ambrósio J, Antunes P, Pombo J, Pombo J. On the requirements of interpolating polynomials for path motion constraints. Mech. Mach. Sci., vol. 26, 2015. doi:10.1007/978-3-319-10723-3_19.

[22] Sequeira B, Pombo J, Antunes P, Ambrósio J, Woodward P. Development of a Methodology for the Geometric Parameterization of Three-Dimensional Tracks. Civil-Comp Proc., vol. 108, 2015. doi:10.4203/ccp.108.133.

[23] Wang Z, Mei G, Xiong Q, Yin Z, Zhang W. Motor car-track spatial coupled dynamics model of a high-speed train with traction transmission systems. Mech Mach Theory 2019;137:386-403. doi:10.1016/j.mechmachtheory.2019.03.032.

[24] Allota B, Conti R, Meli E, Pugi L, Ridolfi A. Railway Vehicle Dynamics under Degraded Adhesion Conditions: An Innovative HIL Architecture for Braking Tests on Full-Scale Roller-Rigs. Int J Railw Technol 2013;2:21-53. doi:10.4203/ijrt.2.3.2.

[25] Ambrósio J, Rauter F, Pombo J, Pereira M. Dynamics of high-speed train pantograph-catenary co-simulation of finite element and multibody codes. AIP Conf. Proc., vol. 1233, 2010. doi:10.1063/1.3452168.

[26] Liu Z., Stichel S, Rønnquist A. A Numerical Study on Pantograph Raising and Lowering in Multi-Pantograph Operation. Int J Railw Technol 2017;6:51-69. doi:10.4203/ijrt.6.3.3.

[27] Song Y, Antunes P, Pombo J, Liu Z. A methodology to study high-speed pantograph-catenary interaction with realistic contact wire irregularities. Mech Mach Theory 2020;152:103940. doi:10.1016/j.mechmachtheory.2020.103940.

[28] Ambrósio J, Rauter F, Pombo J, Pereira M. A Flexible Multibody Pantograph Model for the Analysis of the Catenary-Pantograph Contact. Comput. Methods Appl. Sci., vol. 23, 2011, p. 1-27. doi:10.1007/978-90-481-9971$6 \_1$.

[29] Antunes P, Ambrósio J, Pombo J, Facchinetti A. A new methodology to study the pantograph-catenary dynamics in curved railway tracks. Veh Syst Dyn 2019. doi:10.1080/00423114.2019.1583348.

[30] Nåvik P, Rønnquist A, Stichel S. Variation in predicting pantograph-catenary interaction contact forces, numerical simulations and field measurements. Veh Syst Dyn 2017;55:1265-82. doi:10.1080/00423114.2017.1308523.

[31] Pombo J, Antunes P. A Comparative Study between Two Pantographs in Multiple Pantograph High-Speed Operations. Int J Railw Technol 2013;2:83- 
108. doi:10.4203/ijrt.2.1.4.

[32] Rønnquist A, Nåvik P. Vertical vs. Lateral Dynamic Behaviour of Soft Catenaries subject to Regular Loading using Field Measurements. Int J Railw Technol 2017;6:39-59. doi:10.4203/ijrt.6.2.3.

[33] Antunes P, Ambrósio J, Pombo J. Catenary Finite Element Model Initialization using Optimization. Civil-Comp Proc., vol. 110, 2016. doi:10.4203/ccp.110.106.

[34] Frøseth GT, Nåvik P, Rønnquist A. Operational Displacement Estimations of Railway Catenary Systems by Photogrammetry and the Integration of Acceleration Time Series. Int J Railw Technol 2017;6:71-92. doi:10.4203/ijrt.6.3.4.

[35] Ambrósio J, Pombo J, Pereira M, Antunes P, Mósca A. Recent developments in pantograph-catenary interaction modelling and analysis. Int J Railw Technol 2012;1:249-78. doi:10.4203/ijrt.1.1.12.

[36] Nguyen K, Goicolea JM, Galbadon F. Dynamic effect of high speed railway traffic loads on the ballast track settlement. Congr Métodos Numéricos Em Eng 2011.

[37] Bosso N, Gugliotta A, Zampieri N. A Comprehensive Strategy to Estimate Track Condition and its Evolution. Int J Railw Technol 2012;1:1-19. doi:10.4203/ijrt.1.2.1.

[38] Indraratna B, Nimbalkar S, Rujikiatkamjorn C. Modernisation of Rail Tracks for Higher Speeds and Greater Freight. Int J Railw Technol 2013;2:1-20. doi:10.4203/ijrt.2.3.1.

[39] Fortunato E, Paixão A, Calçada R. Railway Track Transition Zones: Design, Construction, Monitoring and Numerical Modelling. Int J Railw Technol 2013;2:33-58. doi:10.4203/ijrt.2.4.3.

[40] Mezher SB, Connolly DP, Woodward PK, Laghrouche O, Pombo J, Costa PA. Railway critical velocity - Analytical prediction and analysis. Transp Geotech 2016;6:84-96. doi:10.1016/j.trgeo.2015.09.002.

[41] Momoya Y, Nakamura T, Fuchigami S, Takahashi T. Improvement of Degraded Ballasted Track to Reduce Maintenance Work. Int J Railw Technol 2016;5:31-54. doi:10.4203/ijrt.5.3.2.

[42] Woodward PK, Laghrouche O, Mezher SB, Connolly DP. Application of Coupled Train-Track Modelling of Critical Speeds for High-Speed Trains using Three-Dimensional Non-Linear Finite Elements. Int J Railw Technol 2015;4:1-35. doi:10.4203/ijrt.4.3.1.

[43] Antunes P, Magalhães H, Ambrósio J, Pombo J, Costa J. A co-simulation approach to the wheel-rail contact with flexible railway track. Multibody Syst Dyn 2019;45:245-72. doi:10.1007/s11044-018-09646-0.

[44] Pombo J, Almeida T, Magalhães H, Antunes P, Ambrósio J. Finite Element Methodology for Flexible Track Models in Railway Dynamics Applications. Int J Veh Struct Syst 2013;5. doi:10.4273/ijvss.5.2.01.

[45] Costa J, Antunes P, Magalhães H, Pombo J, Ambrósio J. A novel methodology to automatically include general track flexibility in railway vehicle dynamic analyses. Proc Inst Mech Eng Part F J Rail Rapid Transit 2020:095440972094542. doi:10.1177/0954409720945420. 
[46] Costa J, Antunes P, Magalhães H, Ambrósio J, Pombo J. Development of Flexible Track Models for Railway Vehicle Dynamics Applications. CivilComp Proc., vol. 110, 2016. doi:10.4203/ccp.110.98.

[47] Sainz-Aja J, Pombo J, Tholken D, Carrascal I, Polanco J, Ferreño D, et al. Dynamic calibration of slab track models for railway applications using fullscale testing. Comput Struct 2020;228:106180. doi:10.1016/j.compstruc.2019.106180.

[48] Bian X, Jiang H, Cheng C, Chen Y, Chen R, Jiang J. Full-scale model testing on a ballastless high-speed railway under simulated train moving loads. Soil Dyn Earthq Eng 2014;66:368-84. doi:10.1016/j.soildyn.2014.08.003.

[49] Tarifa M, Zhang X, Ruiz G, Poveda E. Full-scale fatigue tests of precast reinforced concrete slabs for railway tracks. Eng Struct 2015;100:610-21. doi:10.1016/j.engstruct.2015.06.016.

[50] Chen R, Zhao X, Wang Z, Jiang H, Bian X. Experimental study on dynamic load magnification factor for ballastless track-subgrade of high-speed railway. J Rock Mech Geotech Eng 2013;5:306-11. doi:10.1016/j.jrmge.2013.04.004.

[51] Anderson WF, Key AJ. Model Testing of Two-Layer Railway Track Ballast. J Geotech Geoenvironmental Eng 2000;126:317-23. doi:10.1061/(ASCE)1090-0241(2000)126:4(317).

[52] Marolt Čebašek T, Esen AF, Woodward PK, Laghrouche O, Connolly DP. Full scale laboratory testing of ballast and concrete slab tracks under phased cyclic loading. Transp Geotech 2018;17:33-40. doi:10.1016/j.trgeo.2018.08.003.

[53] Pita AL, Teixeira PF, Robuste F. High speed and track deterioration: The role of vertical stiffness of the track. Proc Inst Mech Eng Part F J Rail Rapid Transit 2004;218:31-40. doi:10.1243/095440904322804411.

[54] Sainz-Aja J, Carrascal I, Ferreño D, Pombo J, Casado J, Diego S. Influence of the operational conditions on static and dynamic stiffness of rail pads. Mech Mater 2020;148:103505. doi:10.1016/j.mechmat.2020.103505.

[55] Colaço A, Costa PA, Connolly DP. The influence of train properties on railway ground vibrations. Struct Infrastruct Eng 2016;12:517-34. doi:10.1080/15732479.2015.1025291.

[56] Pombo J, Ambrósio J, Silva M. A new wheel-rail contact model for railway dynamics. Veh Syst Dyn 2007;45:165-89. doi:10.1080/00423110600996017.

[57] Alonso A, Guiral A, Gimenez JG. Wheel Rail Contact: Theoretical and Experimental Analysis. Int J Railw Technol 2013;2:15-32. doi:10.4203/ijrt.2.4.2.

[58] Pombo J, Ambrósio J. Application of a wheel-rail contact model to railway dynamics in small radius curved tracks. Multibody Syst Dyn 2008;19:91-114. doi:10.1007/s11044-007-9094-y.

[59] Sichani MS, Enblom R, Berg M. Non-Elliptic Wheel-Rail Contact Modelling in Vehicle Dynamics Simulation. Int J Railw Technol 2014;3:77-96. doi:10.4203/ijrt.3.3.5.

[60] Marques F, Magalhães H, Liu B, Pombo J, Flores P, Ambrósio J, et al. On the generation of enhanced lookup tables for wheel-rail contact models. Wear 2019;434-435:202993. doi:10.1016/j.wear.2019.202993. 
[61] Meymand SZ, Keylin A, Ahmadian M. A survey of wheel-rail contact models for rail vehicles. Veh Syst Dyn 2016;54:386-428. doi:10.1080/00423114.2015.1137956.

[62] Marques F, Magalhães H, Pombo J, Ambrósio J, Flores P. Utilization of NonConformal Wheel Surfaces for Railway Dynamics. Mech. Mach. Sci., vol. 73, 2019, p. 3291-300. doi:10.1007/978-3-030-20131-9_325.

[63] Marques F, Magalhães H, Pombo J, Ambrósio J, Flores P. A threedimensional approach for contact detection between realistic wheel and rail surfaces for improved railway dynamic analysis. Mech Mach Theory 2020;149:103825. doi:10.1016/j.mechmachtheory.2020.103825.

[64] Pombo J, Ambrósio J. An alternative method to include track irregularities in railway vehicle dynamic analyses. Nonlinear Dyn 2012;68:161-76. doi:10.1007/s11071-011-0212-2.

[65] Vollebregt EAH, Steenbergen MJMM. A Methodology for Assessing Track Irregularities with respect to Rail Damage. Int J Railw Technol 2015;4:85105. doi:10.4203/ijrt.4.4.5.

[66] Baier M, Rulka W, Abel D. Model Based Measurement of Railway Track Irregularities. IFAC Proc Vol 2009;42:257-62. doi:10.3182/20090902-3-US2007.0013.

[67] Haigermoser A, Luber B, Rauh J, Gräfe G. Road and track irregularities: measurement, assessment and simulation. Veh Syst Dyn 2015;53:878-957. doi:10.1080/00423114.2015.1037312.

[68] Braghin F, Lewis R, Dwyer-Joyce RS, Bruni S. A mathematical model to predict railway wheel profile evolution due to wear. Wear 2006;261:1253-64. doi:10.1016/j.wear.2006.03.025.

[69] Pombo J, Ambrósio J, Pereira M, Lewis R, Dwyer-Joyce R, Ariaudo C, et al. Development of a wear prediction tool for steel railway wheels using three alternative wear functions. Wear 2011;271. doi:10.1016/j.wear.2010.10.072.

[70] Six K, Meierhofer A, Trummer G, Marte C, Müller G, Luber B, et al. Classification and Consideration of Plasticity Phenomena in Wheel-Rail Contact Modelling. Int J Railw Technol 2016;5:55-77. doi:10.4203/ijrt.5.3.3.

[71] Pombo J, Ambrósio J, Pereira M, Verardi R, Ariaudo C, Kuka N. Influence of track conditions and wheel wear state on the loads imposed on the infrastructure by railway vehicles. Comput. Struct., vol. 89, 2011, p. 1882-94.

[72] Kuka N, Verardi R, Ariaudo C. Wheel Wear Prediction on Trains using InHouse and Commercial Softwares. Int J Railw Technol 2014;3:43-71. doi:10.4203/ijrt.3.4.3.

[73] Pombo J, Ambrósio J, Pereira M, Lewis R, Dwyer-Joyce R, Ariaudo C, et al. A study on wear evaluation of railway wheels based on multibody dynamics and wear computation. Multibody Syst Dyn 2010;24:347-66. doi:10.1007/s11044-010-9217-8.

[74] Sugiyama H, Yada M, Yamamoto H, Kurihara J, Ohbayashi H, Shimokawa Y, et al. Wheel and Rail Profile Wear on Small Radius Curved Tracks and its Effect on Derailment Coefficients: Measurement and Simulation. Int J Railw Technol 2013;2:85-98. doi:10.4203/ijrt.2.4.5.

[75] Pombo J, Ambrósio J, Pereira M, Lewis R, Dwyer-Joyce R, Ariaudo C, et al. 
A railway wheel wear prediction tool based on a multibody software. J Theor Appl Mech 2010;48.

[76] Ekberg A, Akesson B, Kabo E. Wheel/rail rolling contact fatigue - Probe, predict, prevent. Wear 2014;314:2-12. doi:10.1016/j.wear.2013.12.004.

[77] Hossein-Nia S, Sichani MS, Stichel S, Casanueva C. Wheel life prediction model - an alternative to the FASTSIM algorithm for RCF. Veh Syst Dyn 2018;56:1051-71. doi:10.1080/00423114.2017.1403636.

[78] Grassie SL. Rail corrugation: advances in measurement, understanding and treatment. Wear 2005;258:1224-34. doi:10.1016/j.wear.2004.03.066.

[79] Jin XS, Li W, Wen ZF, Wang HY, Sheng XZ. An Investigation into Rail Corrugation, its Mechanisms and Effects on the Dynamic Behavior of Metro Trains and Tracks in China. Int J Railw Technol 2016;5:1-29. doi:10.4203/ijrt.5.3.1.

[80] Grassie SL, Kalousek J. Rail Corrugation: Characteristics, Causes and Treatments. Proc Inst Mech Eng Part F J Rail Rapid Transit 1993;207:57-68. doi:10.1243/PIME_PROC_1993_207_227_02.

[81] Hsu SS, Fagan N. Improving Switches and Crossings Performance and Reliability. Int J Railw Technol 2016;5:79-93. doi:10.4203/ijrt.5.3.4.

[82] Coleman I, Kassa E, Smith R. Wheel-Rail Contact Modelling within Switches and Crossings. Int J Railw Technol 2012;1:45-66. doi:10.4203/ijrt.1.2.3.

[83] Hölscher P. The Dynamics of Foundations for High Speed Lines on Soft Soils. Int J Railw Technol 2012;1:147-66. doi:10.4203/ijrt.1.1.7.

[84] Sañudo R, Markine V, Pombo J. Study on Different Solutions to Reduce the Dynamic Impacts in Transition Zones for High-Speed Rail. J Theor Appl Vib Acoust 2017;3:199-222. doi:10.22064/tava.2018.80091.1095.

[85] EN 14363. Railway Applications - Testing for the Acceptance of Running Characteristics of Railway Vehicles - Testing for Running behaviour and Stationary Tests 2016.

[86] Dukkipati R, Amyot J. Computer-Aided Simulation in Railway Dynamics. New York: 1988.

[87] Iwnicki S, Spiryagin M, Cole C, McSweeney T. Handbook of Railway Vehicle Dynamics. 2nd ed. CRC Press; 2019. doi:10.1201/9780429469398.

[88] V. Garg, Dukkipati R. Dynamics of Railway Vehicle Systems. Elsevier; 1984. doi:10.1016/B978-0-12-275950-5.X5001-9.

[89] Andersson E, Stichel S, Orvnäs A, Persson R. Towards Higher Speeds with Track-Friendly Bogies. Int J Railw Technol 2012;1:39-63. doi:10.4203/ijrt.1.4.3.

[90] Iwnicki S, Bevan A. Damage to Railway Wheels and Rails: A Review of the Causes, Prediction Methods, Reduction and Allocation of Costs. Int J Railw Technol 2012;1:121-46. doi:10.4203/ijrt.1.1.6.

[91] Magalhães H, Ambrósio J, Pombo J. Railway Vehicle Modelling for the Vehicle-Track Interaction Compatibility Analysis. Proc Inst Mech Eng Part K J Multi-Body Dyn 2016;230:251-67. doi:10.1177/1464419315608275.

[92] EN 15827. Railway Applications - Requirements for Bogies and Running Gears 2011.

[93] IEC 61373. Railway Applications - Rolling Stock Equipment - Shock and 
Vibration Tests 2010.

[94] Lewis R, Dwyer-Joyce R, Olofsson U, Pombo J, Ambrósio J, Pereira M, et al. Mapping railway wheel material wear mechanisms and transitions. Proc Inst Mech Eng Part F J Rail Rapid Transit 2010;224. doi:10.1243/09544097JRRT328.

[95] Rhodes A, Hunt G, Harwood N, Kuka N, Baron L, Borrell J. Track damage comparison between conventional and articulated trains operating on a Great Britain railways 'classic' mainline route and a high-speed route. Proc Inst Mech Eng Part F J Rail Rapid Transit 2019;233:743-61. doi:10.1177/0954409718805256.

[96] Kuka N, Verardi R, Ariaudo C, Pombo J. The Influence of the Maintenance State of Track and Bogie Components on the Track-Vehicle Interaction and Loading. Civil-Comp Proc., vol. 104, 2014. doi:10.4203/ccp.104.269.

[97] EN 13848-1. Railway Applications - Track - Track Geometry Quality - Part 1: Characterisation of Track Geometry 2008.

[98] EN 13848-5. Railway Applications - Track - Track Geometry Quality - Part 5: Geometric Quality Levels - Plain Line 2010.

[99] ORE B176/RP1 Annexe 6. Calculs de Conception er Calculs Justificaifs Concernant le Comportement Dynamique 1989.

\section{Acronyms}

$\begin{array}{ll}\mathrm{CD} & \text { Cant Deficiency } \\ \Delta \mathrm{P} / \mathrm{P}_{0} & \text { Wheel unloading, } \Delta \mathrm{P}=\mathrm{P}-\mathrm{P}_{0} \\ \gamma_{\mathrm{eq}} & \text { Equivalent conicity according to EN15302 } \\ \mathrm{MBS} & \text { Multi-Body Simulation } \\ \mathrm{NCA} & \text { Non Compensated Acceleration (by the cant in curve) } \\ \mathrm{P} & \text { Dynamic vertical wheel force } \\ \mathrm{P}_{0} & \text { Nominal static vertical wheel force } \\ \mathrm{P}_{\mathrm{F} 0} & \text { Nominal static vertical wheelset force (EN 14363) } \\ \mathrm{PSD} & \text { Power Spectral Density function } \\ \mathrm{RCC} & \text { Rate of Change of Cant according to EN13803-1 } \\ \mathrm{S} 1002 & \text { Wheel tread profile according to EN13715 and in conformity with } \\ & \text { UIC Leaflet 510-2 } \\ \Sigma \mathrm{Y}_{\mathrm{qst}} & \text { Sum of quasi-static values (50 } \\ & \text { and percentile) of guiding forces of left } \\ \Sigma \mathrm{Y}_{\max } & \text { Sum of maximum guiding forces of left and right wheel used for } \\ & \text { assessing compliance with regard to the safety against track shifting } \\ \Sigma \mathrm{Y}_{\text {lim }} & =(10 \mathrm{kN}+\mathrm{P} 0 / 3) \text { Maximum admissibile value of } \Sigma \mathrm{Y}_{\text {max }} \text { according to } \\ & \text { EN14363 }\end{array}$

